Tortosa Cuesta, Rubén.

Profesor Universitat Politècnica de València

Sánchez López, Miguel.

Profesor Universitat Politècnica de València.

Meléndez Cardona, Ronald.

Alumno Universitat Politècnica de València.

\title{
De la pantalla (bits) al acontecimiento (átomos).
}

\section{From the screen (bits) to the event (atom).}

\author{
TIPO DE TRABAJO: \\ Comunicación. \\ PALABRAS CLAVE: \\ Pantalla, digital, acontecimiento, arte, mirada.
}

KEY WORDS:

Screen, Digital, Event, Art, Look.

RESUMEN.

Ahora más que nunca la imagen la vemos en su primer estado: el virtual (pantalla). Además de ser unos devoradores de imágenes compulsivos, tenemos la necesidad de fijar esas imágenes más allá de la virtualidad en el que nuestro hemisferio derecho del cerebro las procesa y el izquierdo las analiza y las conceptualiza. Es por ello que, a lo largo de nuestro recorrido como seres humanos, no nos hemos conformado con la capacidad de la visión latente, esa que es de la retina (percibe por los ojos mediante la acción de la luz) y el pensamiento. Por el contrario nos hemos esforzado en retener y decidir fijar la imagen para entrar en su tiempo (mirar). Vivimos mirando y buscando zonas intermedias de comunicación, motivados por un intento no tanto de identificar, ni hallar, ni descubrir, sino de mirar para poder fijar la imagen, entenderla, traducirla y habitarla a partir de la experiencia de mirar (registrar). La pregunta surge cuando caemos en la cuenta de que esta experiencia está cambiando. Entre la realidad y nosotros se interponen las pantallas. Ya no es solo una superficie rectangular y plana situada a una cierta distancia de nuestros ojos. Es por donde nos comunicamos, por donde trabajamos y donde se construyen las imágenes. Vemos a través de ellas, y ellas están transformando nuestra mirada aportando nuevas formas de representar (visualizar) y de interactuar con el entorno.

La obra "20.000 pies de Altura o la Memoria Ínfima", va a servirnos de ejemplo del paso de los bits a los átomos y de la visualización de datos para generar una obra como acontecimiento. En ella la exactitud de la luz se traduce en pigmento, formalizando la huella y descubriéndonos el aspecto más sensible del paso de lo virtual a lo real.

\section{ABSTRACT.}

Now more than ever images are watched in its primary state: the virtual one (screen). Besides being compulsive image consumers, we need to set these images beyond the virtual state of our right brain processing for the left brain to analyze and conceptualize them. That is the reason why, along our long journey as humans, we did not settle with our latent capacity of vision, the one provided by our retina (sensed by our eyes due to light) and our thought process. On the contrary, we have focused in retaining and deciding to store that image with the goal of entering into its time (to look). We live looking around and searching for intermediate zones of communication in an attempt not so much of identifying, nor finding out, nor discovering but to watch so we can set the image, understanding it, translating it, and inhabit it from the 
experience of just looking at it (to register). The question arises when we realize the experience is changing. Computer screens are a barrier between us and the reality. They are not only a flat square surface that sits a certain distance from our eyes. They are the window we communicate through, where we work and where images are created. We see through them and they are transforming our sight, bringing in new ways of representing things (to display) and of interacting with our environment.

The artwork "20,000 feet or the tiny memory" is an example of turning bits into atoms and the use of data visualization for creating art as an event. In this work, the accuracy of the light translates into a pigment that shapes the footprint and discovers us the most sensitive aspect of the transition from the virtual to the real world.

\section{CONTENIDO.}

La lente en el siglo XV supuso reconducir la luz desde la escena (realidad) al soporte (fijar la realidad), y con ello uno de los cambios más radicales en la manera de mirar y representar. Siglos más tarde una lente ubicada en un artefacto - la fotografía- supuso una nueva etapa en la mirada del hombre hacia el mundo que le rodeaba, produciéndose un nuevo giro inaudito en la representación que provocó, entre otras cosas, el nacimiento del arte moderno. Se podría pensar en el poder de la tecnología para interceptar la mirada. Empezamos a proyectar la capacidad de nuestra mirada sobre su mirada. Si nuestra mirada se proyecta en el cerebro. ¿Dónde se proyecta su mirada?: en la pantalla.

Infinidad de dispositivos electrónicos están capacitados para registrar y almacenar miles de imágenes virtuales, en un sistema que Manovich caracterizará como el paso de un modo continuo a discreto. En la mayoría de las veces solo vamos a mirarlas en la pantalla unos segundos. "El ver no es sólo acto o experiencia, ahora es, simultáneamente, registro técnico, fijación en memoria externa" ${ }^{1}$. Ello ha provocado una nueva relación con la imagen, en lo que Joan Foncuberta define como Cambio de Umbral y el colapso de la imagen. Como ya anunció la multinacional Sanmsung "La imagen media entre nosotros y el mundo". Registramos imágenes (consideramos que esta acción no es fotografía), sin intención de verlas. No hay tiempo para verlas. Simplemente las almacenamos siendo este acto el que prevalece sobre la imagen. Borges narra las circunstancias en donde la cartografía era una obsesión y los mapas eran perfectamente el territorio. Había que observar y dibujar para poder constatar y dar fe de ese pedazo de tierra. El almacenamiento de ellas se ha convertido en un hecho inconsciente. No hay tiempo de clasificar, nombrar y ordenar. Un no_lugar llamado nube se ha convertido en el mayor cajón de sastre de las imágenes virtuales. La imagen ha perdido el poder de la memoria. Según el diccionario de la Real Academia Española de la Lengua significa: adj. Físico. Que tiene existencia aparente pero no real. "La "virtualidad" de la imagen virtual consiste en que no está allí donde se percibe, se forma tan sólo sobre la retina y no por fuera del ojo en el sitio donde se ve. La percepción visual de ambos, del objeto real y de la imagen virtual, es idéntica. La imagen retiniana no entra en el proceso de clasificación de realidad o virtualidad de la imagen. El ojo está diseñado para recoger haces divergentes de luz y hacerlos converger sobre la retina." ${ }^{2}$. Para José Luís Brea la máquina de ver y producir técnicamente las imágenes que de ese ver resultan, traerá modificaciones que acabarán por prefigurar un orden de la visión radicalmente diferenciado. Los medios lo convierten todo a datos informáticos por lo que son reprogamables. El remix , la recombinación para generar otras imágenes se ha convertido en una práctica habitual de la imagen/pantalla.

La cultura codificada digitalmente habita en el poder de la pantalla que ha colonizado la realidad, presentando una condición que la define como inmaterialmente. Toda la cultura, pasada y presente, se filtra en las pantallas, ya que ésta se encuentra siempre entre en medio de nosotros: Black Mirror, "Es lo que usted encontrará en cada pared, en cada escritorio, en la palma de cada mano: la pantalla fría y brillante de un televisor, un monitor, un teléfono inteligente. ${ }^{3}$ Pantallas que además están interconectadas formando todo un sistema red de conectividad permanente. En palabras de Juan Martín Prada "Todo forma parte ya del mismo sistema, caracterizado por una tendencia a la inclusividad total: todo el mundo debe formar parte de ese sistema de conectividad y debe hacerlo durante todo el tiempo y desde cualquier lugar". 4 Ahora las imágenes dan más realidad que la realidad misma. No existe analogía, no existe reproducción sino una obsesión por visibilizar la intangibilidad de lo que nos hace ver: la luz expandida en el territorio de la creación digital. La imagen efímera fruto de su virtualización ha invadido todo nuestro imaginario y podríamos preguntarnos si todavía nos caben mas imágenes, si no estamos llegando a un punto ciego de la imagen.

\footnotetext{
${ }^{1}$ MARTIN PRADA, Juan Martín. 2010. La Condición Digital de la Imagen. Lumen Ex 2010, Universidad de Extremadura 2010. P. 41 ISBN 978-84-7723-918-5

${ }^{2}$ Nociones básicas de óptica [Consulta 14 de marzo de 2017] . Disponible en:

http://www.medic.ula.ve/histologia/anexos/microscopweb/MONOWEB/capitulo2 4.htm. Última visita 14 de marzo de 2017.

${ }^{3}$ BROOKER, Charlie. [Consulta 25 de febrero de 2017] Creador de la serie Black Mirror. Disponible en:

https://es.wikipedia.org/wiki/Black_Mirror_(serie_de_televisi\%C3\%B3n.

${ }^{4}$ MARTIN PRADA, Juan Martín. 2012. Otro tiempo para el arte. Cuestiones y comentarios sobre el arte actual. Ed. Sendema, Valencia. P. 69. ISBN 978-84-939084-1-6
} 


\begin{abstract}
"A diferencia del modo en que la imagen se daba bajo las condiciones tradicionales de su producción (establemente "consignada" en un soporte material del que era en todo momento indisociable) la e-imagen se da en cambio en condiciones de flotación, bajo la prefiguración del puro fantasma. Digamos que su paso por lo real es necesariamente efímero, falto de duración. Ella comparece, pero para inmediatamente desvanecerse, ceder su lugar a algo otro. Su modo de ser es al mimo tiempo un sustraerse, un estar pero permanentemente dejando de hacerlo."
\end{abstract}

Paradójicamente la inflacción de la imagen/pantalla, esa por donde nos desplazamos, esta generando nuevas actitudes en el marco de la creación artística, apareciendo situaciones en las que el artista quiere extraer la imagen virtual (bits) de la pantalla para convertirla en un hecho físico (átomos) en lo que consideramos el Acontecimiento. Haciendo una analogía con el cine Manovich se expresa: "Los registros de la visión de la cámara se vuelven objetos materiales, compartiendo el espacio con la realidad material que dio origen a dicha visión". ${ }^{6}$

Fijar la imagen, entenderla y habitarla a partir de la experiencia de mirar (registrar), esta provocando todo un sistema de formas traducidas en donde la Transferencia adquiere un lugar importante en los procesos de construcción de la imagen contemporánea. Nicolas Bourriaud la definirá como " Una práctica de desplazamiento, que realza como tal el paso de los signos de un formato a otro".

${ }^{7}$ Estos pasos se convierten en traducciones que según Walter Benjamin, una traducción permite en principio que sobreviva el original sin dejar de implicar la muerte de este. Mediante esta práctica de transferencia los artistas codifican y fijan datos mediante la impresión de éstos en 2D o 3D, para su visualización en un sistema en el que el proceso adquiere el sentido de la obra de arte. Ya no se trata tanto de generar objetos como proceso.

\begin{abstract}
“La imagen abandona así la pantalla del ordenador, ese territorio donde todo lo demás que forma parte de nuestra cultura también tiene lugar, para ubicarse en una superficie exclusiva, dotándose de especificidad como objeto, pudiendo con ello también funcionar en relación a las lógicas espaciales institucionales y comerciales. Finalmente la imagen se ha situado ya en el mismo espacio que ocupa el espectador (en ese otro lado de la pantalla)." ${ }^{8}$
\end{abstract}

La creación se centra en el proceso pasando entre diferentes estados de la imagen que puede terminar en una pantalla, un dibujo sobre un papel, una pintura, la impresión mediante tinta pigmentada sobre un soporte físico o una impresión 3D. A principios del siglo XXI se planteaba el Ser Digital como una condición hacia la virtualidad de la imagen y su pérdida de fisicidad -lo intangible- se estableció como una de sus características. Más bien pensamos que lo digital nos ha mostrado una gran capacidad de hibridación de lenguajes, técnicas y procesos. Pero sobre todo una nueva forma de mirar a través de las pantallas, provocando un cambio en la representación y un nuevo espectro de formas artísticas realmente diversas. Para Peter Weibel "Toda práctica artística sigue hoy el guión de los medios, los progresos de los medios. Este concepto mediático abarca no sólo los antiguos y nuevos medios técnicos, de la fotografía al ordenador, sino también los antiguos medios analógicos como la pintura y la escultura que han cambiado bajo la influencia y presión de los medios técnicos. Por ello es válida la frase: Toda práctica artística sigue el guión de los medios". ${ }^{9}$

La característica actual de la creación es la de conseguir transcender la región en la que la computadora determina la obra y por lo tanto "escapar a los determinismos simples del medio utilizado" ${ }^{10}$. La imagen se ha fragmentado, multiplicado, diversificado en un medio que se constituye virtual y que es pura imagen/luz. El arte ya no habita en un lugar concreto. Las diferentes disciplinas se condicionan mutuamente, y quizás ya no empleamos tanto tiempo en buscar la imagen, (está por todas partes), sino más bien en fijarla en un aquí y un ahora. Para Joan Foncuberta ya no hay que registrar más imágenes puesto que ya existen todas las posibles en el mundo, por lo que ahora hay que "adoptar" las imágenes Es por ello que que sentimos la necesidad de establecer un nuevo escenario en el que la imagen se fija mediante procesos que le dan fisicidad. Imagen-materia o como proclamó Goethe "detente instante, eres tan bello!"

\footnotetext{
${ }^{5}$ BREA, José Luís, 2004. Estudios Visuales Cambio de régimen escópico: del inconsciente óptico a la e-image. CENDEAC. Murcia. P. 153. ISSN 1698-7470

En el texto el término e-imagen se refiere para definir una imagen tiempo, pero que además tiene la potencia de darse como imagendiferencia, como imagen-movimiento. En la e-imagen en efecto la diferencia se despliega no solo en la espacialización única de un ahora cortado, sino también en cuanto a la sucesión en el tiempo de la representación.

${ }_{7}^{6}$ MANOVICH, Lev. 2005. El lenguaje de los nuevos medios de comunicación. Ed. Paidós. Barcelona. P. 139. ISBN 84-493-1769-X

7 BOURRIAUD, Nicolas. 2009. Radicante. Ed. Adriana Hidalgo. Córdoba. P. 162. ISBN 978-84-937140-6-2

${ }^{8}$ PRADA, Juan Martín. Op. Cit. P. 51

${ }^{9}$ WEIBEL, Peter La Condición Posmedial. 2006. Ed. Centro Cultural Conde Duque. Área de las Artes. Madrid. P. 13 ISBN 84-96102-21-1

${ }^{10}$ BOURRIAUD, Nicolas. Ibídem. P 162
} 

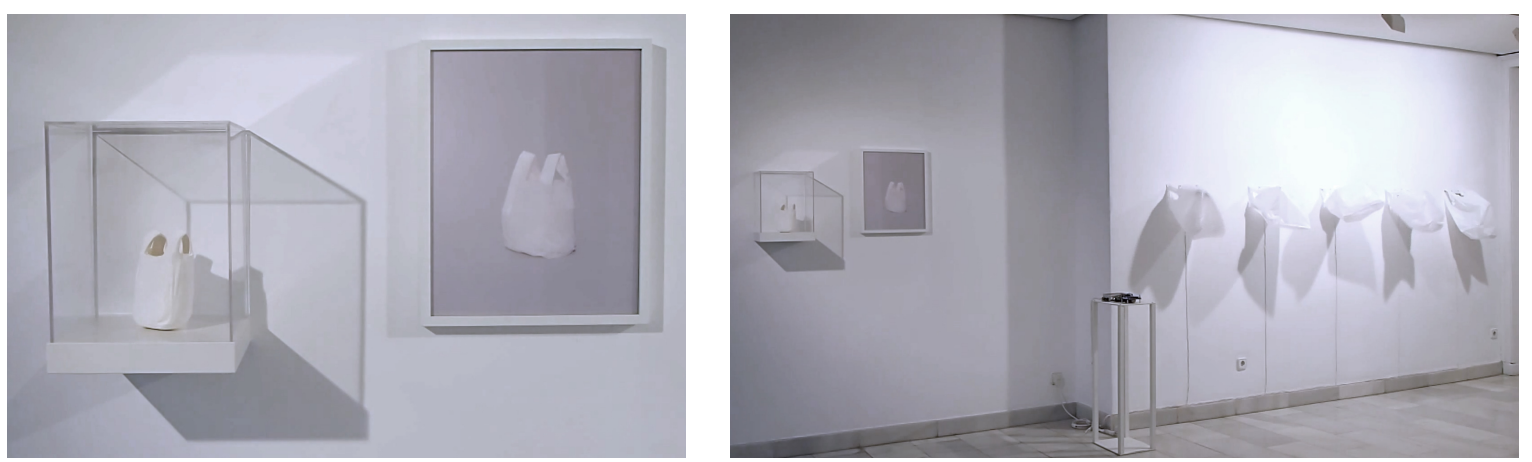

llustración 1. Hugo Martínez Tormo.

Los procesos que nos referimos ponen de manifiesto la traducción y traslación de la imagen en entradas y salidas (imput/output) de lo concreto (analógico) a lo abstracto (digital) y de nuevo su paso final a lo físico, en un medio que reinterpreta varias de sus condiciones como lenguaje hacia nuevos metalenguajes de transcodificación (traducir a otro formato). Por este motivo el concepto de gráfica digital se expande a nuevos territorios. Si bien hasta hace bien poco eran de los sistemas múltiples de reproducción en donde existía físicamente una matriz, , ahora lo entendemos como un sistema de transferencia de información.

"Las imágenes se definen desde ahora por su densidad, por la cantidad de átomos que las componen. ¿Cuántos píxeles (picture elements)? Tal es la nueva condición de lectura y transmisión de las imágenes, centradas en las posibilidades del ordenador, que constituye hay la base de una gramática formal desarrollada por una nueva generación de artistas -que no necesariamente se valen de herramientas digitales- puesto que estas ya pertenecen de lleno a nuestra manera de pensar y representar, de tratar y transmitir informaciones". ${ }^{11}$

De esta manera un medio se anida en el otro en lo que W. J. T. Mitchell define como un trenzado que no deja costuras en el que "La visión natural es en sí misma un trenzado y un anidamiento de lo óptico y lo táctil." ${ }^{12}$ Desde la pantalla hasta depositar el pigmento sobre la materia última, el soporte definitivo, se establece un cuidadoso tránsito surgido de la investigación de los procesos, y de una visión atenta y desacelerada en contraposición a la velocidad en la que estamos inmersos. En su principio era luz emitida y ahora pasa a recibirla otorgando a esta, según el concepto de Juan Martín Prada, la piel de la imagen y que constituye la materia para la mirada.
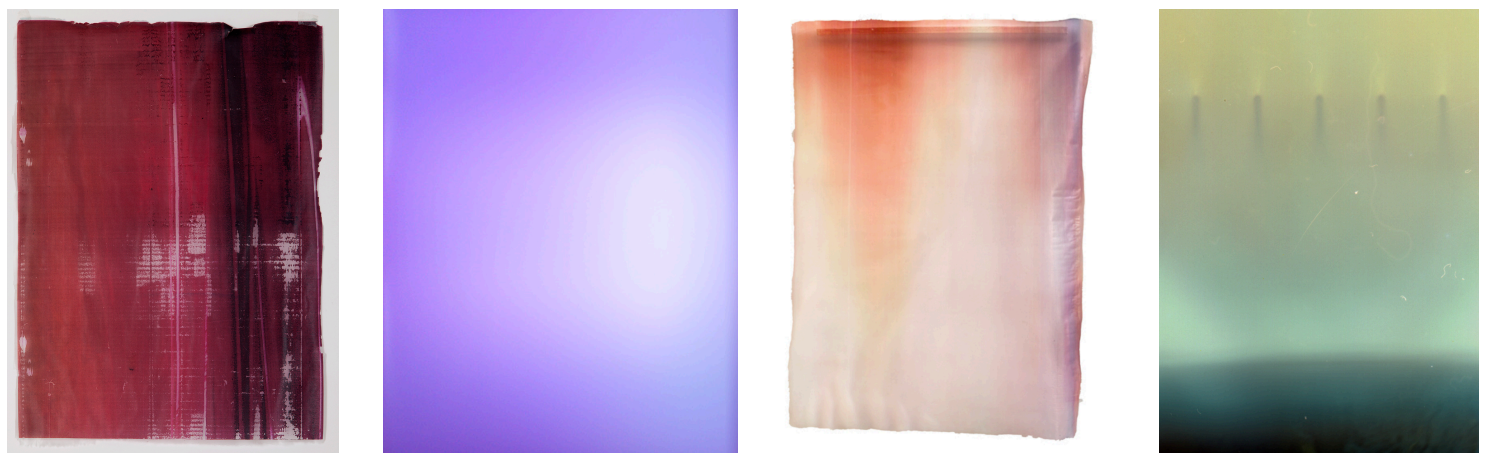

Ilustración 2. Rubén Tortosa, Rita Mass, Inma Femenía, Esther Navarro.

No existe analogía, no existe reproducción sino una obsesión por visibilizar la intangibilidad de lo que nos hace ver: la luz expandida en el territorio de la impresión digital para ser convertida en un tiempo estático, único. Estas series de obras de Rubén Tortosa, Rita Mass, Inma Femenía y Esther Navarro (Ilustración 2), son consecuencia de estos procesos que nos descubren el viaje de la luz de las pantallas al pigmento. En este contexto, José Ramón Alcalá cita como rasgos característicos de la cultura digital: una nueva forma de visibilidad, la levedad de la imagen presidida por la sutileza, la multiplicidad, el ruido, y la fragilidad del soporte liviano y aéreo, que nos revela la exactitud de la luz que hiere la materia, formalizando la huella y descubriéndonos el aspecto más sensible de un instante imprevisible, minúsculo, inevitable, desprovisto de origen y causalidad. Los procesos de producción se establecen a partir de la mediación en la computadora en lo que Lev Manovich define como "extensibilidad permanente". Cualidad que adquiere por la

\footnotetext{
${ }^{11}$ Ibídem. P 156

${ }^{12}$ W. J. T. , Mitchell. 2005. No existen medios visuales en Estudios Visuales. La epistemología de la visualidad en la era de la globalización. Ed. Akal, Madrid. P. 23 ISBN 978-84-460-2323-4
} 
capacidad de agregar nuevas propiedades. Ahora bien, es necesario trascender de la región en que la computadora y sus derivados de procesamiento de datos se utilizan únicamente como un instrumento más.

En esta mezcla de lenguajes, tecnologías y técnicas de los procesos de creación de hoy en día, pretendemos no asociar la creación solo a un medio, en este caso el digital, si no más bien a unas ideas surgidas de la manera que tenemos de mirar hoy en día. Mirada que está totalmente mediatizada por el filtro de la pantalla. Unas pantallas que nos muestran su inconsciente óptico, ya que las imágenes las revela el ojo mecánico (primero la cámara fotográfica) y de las tecnologías y estrategias contemporáneas surgidas de los dispositivos de registro digital (hoy en día: tablets, móviles, cámaras digitales etc.), que visibilizan la imagen como apunta Brea aludiendo a Benjamin "de forma no reflexionante, no capaz de autopensarse y por lo tanto, y de alguna forma, inconsciente.

Estas situaciones están generando nuevos estados de la imagen definidas por las traducciones de unos signos a otros (la obra Celeste de Solimán López es un claro ejemplo de estas traducciones), y una amplia diversidad en la práctica artística, siendo que todas ellas tienen en común su origen en la imagen digitalizada. Pero ahora para que no se diluyan en la ingente cantidad de imágenes que se producen cada segundo, hay que traducirlas: pasar los datos de un lugar a otro.

"Así podríamos traducir el arte de hoy en función de un criterio de traductibilidad: a saber, según la índole de los contenidos que transcodifica, según la manera como los viatoriza y los introduce en una cadena significante. la traducción aparece también hoy como el imperativo categórico de una ética de reconocimiento del otro, mucho más que el mero registro de su "diferencia"”. ${ }^{13}$
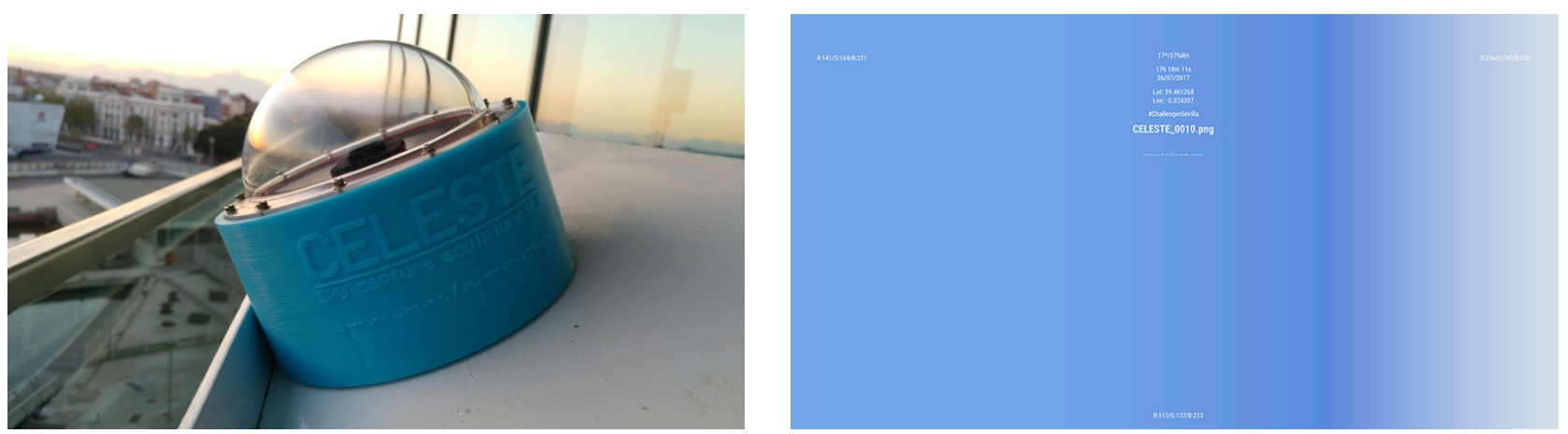

Ilustración 3: Solimán López.

“20.000 pies de Altura o la Memoria Ínfima”.

Visibilizar datos. El espacio aéreo, a veinte mil pies de altura, ejemplifica el discurso que hemos propuesto. La obra bajo el título 20.000 Pies de Altura o la Memoria Ínfima, en la que ha colaborado el Ingeniero Informático Miguel Sánchez, nos remite al viaje y trayecto representado en una acción/eco en el espacio expositivo. Estos trayectos de idas y vueltas, pasando de un código a otro, se convierten en formas traducidas en metáfora de la visualización del espacio-tiempo, de la tecnología su virtualidad y su fisicidad. Sobre un lienzo azul que actúa de ventana/pantalla, lejos de retener lo inmóvil, nos enseña la memoria ínfima de la representación. Los datos adoptados son eficientes aliados de su volatilidad. El proceso que se forma fruto del viaje, se verifica matéricamente. Se compone de un sistema cartesiano de tres ejes sobre guías de aluminio, RaspberryPi, Arduino, fuentes de alimentación y motores, todo ello oculto detrás de un bastidor. En tiempo real va recogiendo información del trayecto del tráfico aéreo por encima de 20.000 pies de altura de donde se encuentra ubicada la obra en ese momento. Estos datos son traducidos en señales que mueven los ejes y que finalmente crean una estela blanca sobre el pigmento azul que va desapareciendo tras de sí al cabo de unos segundos. Los bits se traducen en átomos. De esta forma el proceso genera la imagen, haciéndose y deshaciéndose continuamente sobre el lienzo azul: es la imagen acontecimiento.

\footnotetext{
${ }^{13}$ BOURRIAUD, Nicolas. Ibídem. P. 154
} 

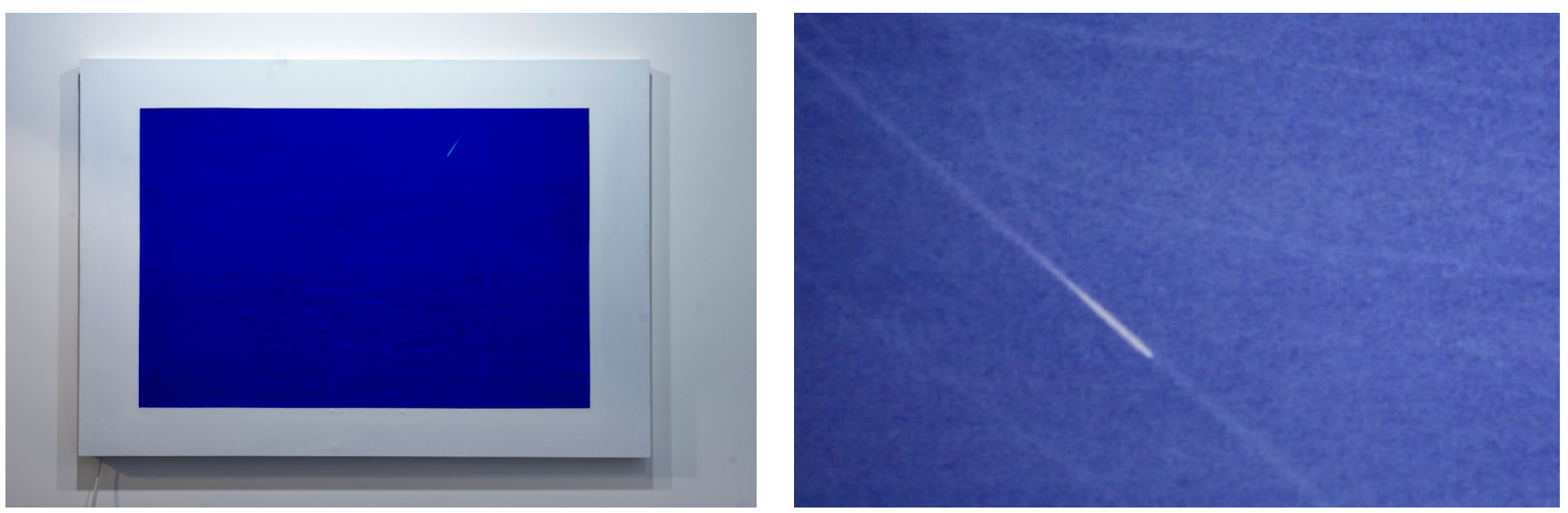

\section{llustración 4: Rubén Tortosa.}

Índice de ilustraciones:

Ilustración 1: Hugo Martínez Tormo 3DsoundPrinter_Plastic Bag. Impresión 3D, Impresión Ink-Jet, Electrónica, Arduino, Motores y bolsas de plástico. Medidas variables. 2017

Ilustración 2: Rubén Tortosa. Error. Imagen digital transferida sobre poliuretano. 42×29. 2007; Rita Mass. Miss/Take Untitled 14.10 8/20/09, 10-21-56 AM. Impresión Ink-Jet. 2009; Esther Navarro S/T de la serie Donde nace la luz. Impresión digital transferida sobre resina epoxi. 18x12. 2015; Inma Femenía, Interval 09.04 .129 a.m. hasta 10.45 p.m. Impresión digital transferida sobre poliuretando. $29 \times 21.2012$.

Ilustración 3: Solimán López Celeste. Impresión 3D, RaspberryPi, Arduino, Cámara, Pantalla, Impresión Ink jet. Medidas variables 2017.

Ilustración 4: Rubén Tortosa 20.000 pies de altura o la memoria ínfima. Lienzo sobre bastidor, RaspberryPi, Arduino, Fuentes alimentación, motores guías aluminio. 140×190. 2016 